THURSDAY, APRIL I2, 1883

\section{THE VIVISECTION BILL}

THE failure of Mr. Reid's Vivisection Abolition Bill on April 4 affords cause of congratulation to all who are interested in science, although it is perhaps to be regretted that the Bill did not come to a "division" instead of being "talked out." Scientific men must be pleased because one more attempt of ignorance to stop the pursuit of knowledge has been defeated. But, more than this, the failure of the Bill is a boon to all who care for their own health, for that of their families, and for the welfare of society at large. Had it passed it would not only have stopped all experiments in physiology, pathology, and pharmacology in this country, but it would have rendered impossible the detection of crime by the application of physiological tests. Had this Bill been law at the time of the trial of Lamson for poisoning by aconite, his conviction would have been impossible ; for although chemical evidence pointed to aconite as the poison used, the tests for it were not sufficiently distinctive to have justified his conviction on chemical evidence alone, and it required to be corroborated by physiological evidence. This was afforded by the injection of the substance obtained from the stomach into some small animals. As these died presenting all the symptoms of aconitine poisoning, the chemical evidence was confirmed, and the poisoner was accordingly convicted.

Under the present law, considerable delay was caused before a certificate could be obtained to allow these experiments to be performed, but if Mr. Reid's Bill had been law, they could not have been performed at all ; and secret poisoners secure of immunity might have become as common in this country as they were in the days of the Borgias.

To understand thoroughly the effect of the Bill upon medical science and practice, we must imagine to ourselves what would occur if experiments were stopped not only in this country but in others ; for it is not alone in this country that the opponents of vivisection are active; they are endeavouring to stop it as far as they can in America and on the Continent also.

Last week we published some facts and considerations regarding vivisection and its relations to medicine, issued by the Association for the Advancement of Science by Research. The data there contained we should think were sufficient to convince any reasonable person of the advantages that medicine has derived from experiments on animals. But it is curious to notice the way in which they are regarded by anti-vivisectionists. Finding themselves in many cases unable to deny the advantages of the knowledge which has been obtained by experiments, they say this knowledge might have been got without experiments, and so it might, if man had been differently constituted. But being as he is, there is no royal road to knowledge, and he must take the only one which is available for him-that of experiment.

As Mr. Cartwright pointed out in his speech, if experiments on animals are prohibited, experiments must be made on human beings, and in their rudest form. The contrast between such rude popular experiments on man

VOL. XxVII.-No. 702 and scientific experiments on animals was illustrated in a speech of Dr. Lyon Playfair in reference to these two kinds of experiments on cholera. The first experiment was tried on 500,000 human beings in London, who were supplied with water contaminated by choleraic discharges with the result that 125 out of every 10,000 consumers died from the effects of the experiment. In two other experiments made by another water company, 180 died in the first experiment, and 130 in the second, out of every Io, 000 .

These popular experiments on a large scale involved the sacrifice of half-a-million human beings. In contrast with this may be taken the scientific experiments made upon animals by Thiersch and others. These experiments were made on 56 mice, I4 of which died from the choleraic discharges. These were not mixed with water accidentally or carelessly, as in the popular experiment, but were administered under definite conditions, and the effect watched. The results of these experiments showed that water contaminated with choleraic discharges was deadly; the water so contaminated was avorded, and an epidemic was escaped.

The common-sense conclusion on the whole matter was expressed by the Home Secretary, who said that he disliked as much as any man in the House the infliction of pain upon animals, but felt satisfied that under the administration of the law at present there was very little pain inflicted upon animals, and that pain was inflicted under such circumstances as to guarantee that it was not wantonly inflicted, but that it had occurred in the course of experiments that were abundantly justified for the benefit of bumanity at large. As a guarantee that no experiments shall be performed that are not abundantly justified, Sir W. Harcourt has made the agreement with the Association for the Advancement of Science by Research, that, "if they will undertake the task of reporting to him upon the experiments, he will undertake that no certificate shall be granted except on a previous recommendation from them." This Association is a representative body of the whole medical profession, being composed of the Presidents of the Royal College of Physicians and Surgeons of London, Edinburgh, and Dublin, of the Royal Society of London, of the Medical Council, and of all the chief medical associations and societies, along with some others specially elected. It would be difficult to imagine a body better adapted for the purposes of maintaining the high character of the profession for humanity, by preventing any wanton infliction of pain upon animals by experiment, whilst at the same time preventing the serious consequences to human health and life which would ensue if properly devised experiments were prohibited by ill-judged and excessive care for animals.

\section{THE BRITISH NAVY}

The British Navy: its Strength, Resources, and Administration. By Sir Thomas Brassey, K.C.B., M.P. Vols. I., II., III. (London: Longmans, Green, and Co., 1882.)

THE three volumes of this work already given to the public by Sir Thomas Brassey are to be followed by three others; but as these are to contain reprints of speeches and publications on naval affairs it is preferable B B 